\title{
Frequency of Poor Sleep Quality and Related Factors in Geriatric Patients
}

\author{
(1) İbrahim Halil Türkbeyler¹, (1) Ahmet Çiğiloğlu², (1) Eyyüp Murat Efendioğlu², (1) Zeynel Abidin Öztürk² \\ ${ }^{1}$ Dr. Ersin Arslan Training and Research Hospital, Clinic of Internal Medicine, Division of Geriatrics, Gaziantep, Turkey \\ ${ }^{2}$ Gaziantep University Faculty of Medicine, Department of Internal Medicine, Division of Geriatric Medicine, Gaziantep, Turkey
}

\begin{abstract}
Objective: Sleep is a necessary and indispensable activity of human life, and it is a physiological need as crucial as eating, drinking, breathing and excretion. This study aims to investigate the frequency of poor sleep quality and related factors in patients admitted to a geriatric outpatient clinic.

Materials and Methods: The study was performed by a retrospective file scanning method. It included 100 random geriatric patients who applied to the geriatric outpatient clinic. The data were collected using the "comprehensive geriatric assessment form" and the "Pittsburgh Sleep Quality scale" and evaluated using SPSS version 22.0.

Results: Poor sleep quality was detected in $60 \%$ of patients. Geriatric patients with poor sleep quality had increased frequency in obesity and polypharmacy, increased Geriatric Depression scale scores, lower handgrip strength and decreased walking speed that were statistically significant $(\mathrm{p}<0.005)$.

Conclusion: We have shown that at least half of geriatric patients might have poor sleep quality associated with multiple clinical conditions. Sleep disorders are important health problems affecting the geriatric individuals' quality of life and well-being. Asking pertinent questions to treat poor sleep quality effectively is recommended to increase this population's quality of life and well-being.
\end{abstract}

Keywords: Sleep quality, obesity, polypharmacy, depression, elderly

\section{Introduction}

The phenomenon of aging, which is more prominent in developed countries, is also gaining importance for developing countries; and hereby geriatric population is ever-increasing in our country. As the world population progresses to an older population pattern day by day, the frequency of chronic diseases increases concordantly, and measures on quality of life criteria, such as healthy living, healthy aging also start to come to the agenda (1).

Covering $1 / 3$ of the human life cycle and ensuring the continuity of health, sleep is considered as one of the basic physiological needs of mankind (2). Geriatric individuals experience excessive daytime sleepiness in relation to the decrease in sleep quality. In addition to productivity and efficiency, sleep also affects cognitive functions (e.g. memory, concentration) positively and contributes to the physical and psychological restoration (3). Because of these positive effects, sleep is considered as an important health variable affecting the individual's quality of life and well-being.

Regular sleep routine has such positive effects on human life; therefore its disruptions affect individuals negatively and causes problems such as lack of attention, anxiety, depression, increased sensitivity to pain, irritability, hallucinations, loss of appetite, difficulty in excretion, memory disorders, increased risk of falls and decreased physical activity. Problems that arise due to sleep disorders lead to impaired quality of life and increased morbidity and mortality rates (4).

Sleep disorders such as difficulty in falling asleep and maintaining sleep, frequent awakening, and restless legs

Address for Correspondence: Ahmet Çiğiloğlu, Gaziantep University Faculty of Medicine, Department of Internal Medicine, Division of Geriatric Medicine, Gaziantep, Turkey

Phone: +90 5302449074 E-mail: cigiloglu@yahoo.com ORCID: orcid.org/0000-0002-2307-8682

Received: 06.09.2020 Accepted: 06.10.2020

Cite this article as: Türkbeyler ï, Çiğioğlu A, Efendioğlu EM, Öztürk ZA. Frequency of Poor Sleep Quality and Related Factors in Geriatric Patients. Eur J Geriatr Gerontol 2021;3(1):12-17

๑Copyright 2021 by the Academic Geriatrics Society / European Journal of Geriatrics and Gerontology published by Galenos Publishing House. 
syndrome are frequent in geriatric patients. In addition to chronic diseases, these problems negatively affect functionality and quality of life. This study was planned in order to investigate the frequency of poor sleep quality and related factors in this population.

\section{Materials and Methods}

This study was planned with a retrospective file scanning method to investigate the frequency of poor sleep quality and related factors in 100 patients who applied to the Geriatric Outpatient Clinic of Gaziantep University Research and Application Hospital for any reason. The data were collected using the "comprehensive geriatric assessment form" and "Pittsburgh Sleep Quality scale (PSOl)". PSOI was developed in 1989 by Buysse et al. (5). PSOl has 7 components, and each component is rated between 0 and 3 points. The total score ranges from 0 to 21 (6). A total score higher than 5 indicates poor sleep quality (7).

As parts of the Comprehensive Geriatric Assessment, the Geriatric Depression scale (GDS) with 15 questions, the minimental state examination (MMSE), Barthel index of activities of daily living (ADL), Lawton\&tBrody index of the instrumental activities of daily living (IADL), and short form of the mini nutritional assessment tool-short form (MNA-SF) were used.

GDS scores of 5 and over indicate depression (8). MMSE assess five different areas in cognitive functions such as orientation, registration, attention and calculation, recall and language. MMSE scores of 24 and below were considered as impaired, suggesting dementia (9).

Barthel index of ADL was used for evaluating subjects' physical disability. This scale includes dressing, bathing, grooming, using the toilet, eating, transffering and incontinence (10). Scores can range from 0 to 100 and higher scores indicate higher independence.

Lawton\&Brody index was used to evaluate the disability in IADL and this scale aims to find out subject performance in the following activities; doing laundry, shopping, taking medicine, housekeeping, food preparation, using the telephone, using transportation, and managing money. Higher scores indicates higher independence (11). The nutritional status of participants was determined by using MNA-SF. It is a simple and validated screening tool for nutritional risk and if the score was $\leq 7$, it is accepted as malnutrition (12).

Although there is no consensus on the definition of "polypharmacy" ", which refers to the use of multiple drugs in the elderly, it usually means the use of many drugs for more than one indication at the same time. In our study, we used the National Service Framework definition of polypharmacy as four or more drugs usage.
Individuals with established adverse drug effects on sleep were excluded from the study. Evaluation scales were applied by face to face interview techniques. Ethical approval was obtained. The study was carried out in accordance with the Helsinki Declaration.

\section{Statistics}

The data were analyzed with IBM SPSS Statistics version 22.0. Descriptive (number, percentage, mean and standard deviation) and parametric tests were used for the analysis. T-test or MannWhitney $\mathrm{U}$ tests were used to compare continuous parameters between groups with and without sleep quality and groups by gender. Chi-square test was used to compare categorical parameters. A p-value of less than 0.05 was considered significant.

\section{Results}

A total of 100 random patients admitted to the geriatric outpatient clinic were included in the study. The mean age was $71.17 \pm 5.49$ (65-89 years). $56 \%$ were women (56) and $44 \%$ were men (44). The mean PSOI score was $6.17 \pm 3.79$, and the lowest and highest scores were 0 and 16 , respectively. The PSOI score of $60 \%$ of the group was between 5-16, and these individuals had poor sleep quality. $75.9 \%$ of women and $38.1 \%$ of men had poor sleep quality $(p<0.005)$. The comprehensive geriatric evaluation results are summarized in Table 1.

Age, marital status, educational status, lifestyle, smoking, drinking alcohol, regular exercise, scores of the $A D L$, Mininutritional assessment and MMSE, and presence of chronic disease showed no significant difference between groups with and without poor sleep quality ( $p>0.05)$.

It was found that geriatric patients who had significant poor sleep quality showed more frequent high body mass index (BMI) and obesity, increased drug use and polypharmacy, increased score of the Geriatric Depression scale, low handgrip strength, and relative incompetence in instrumental $A D L(p<0.005)$ (Table 2).

\section{Discussion}

Sleep is a daily life activity that is one of the basic needs of humans. Therefore, sleep is seen as an important variable of health, affecting the quality of life and well-being of the individual.

Sleep, which constitutes an important part of human life has attracted the attention of many researchers. It is noteworthy that $60 \%$ of patients who applied to the geriatric outpatient clinic have poor sleep quality in our study.

Sleep problems are an inevitable part of the aging process and are manifested by a decrease in the sleep quality of 
individuals (13). In the literature, there are studies showing that $50 \%$ to $77 \%$ of elderly individuals have sleep problems $(14,15)$. $60 \%$ of the individuals who participated in our study had sleep problems. This supports the results of the studies that previously examined the prevalence of sleep problems of elderly individuals.

Adequate sleep is important for the renewal of the body, regular brain functions, energy storage, good appearance, and protection from diseases. It was determined that sleep time and quality affect memory, learning, performance, metabolic and endocrine system, and decrease in sleep time disrupts neurohormonal balance, causes weight gain and obesity (16).

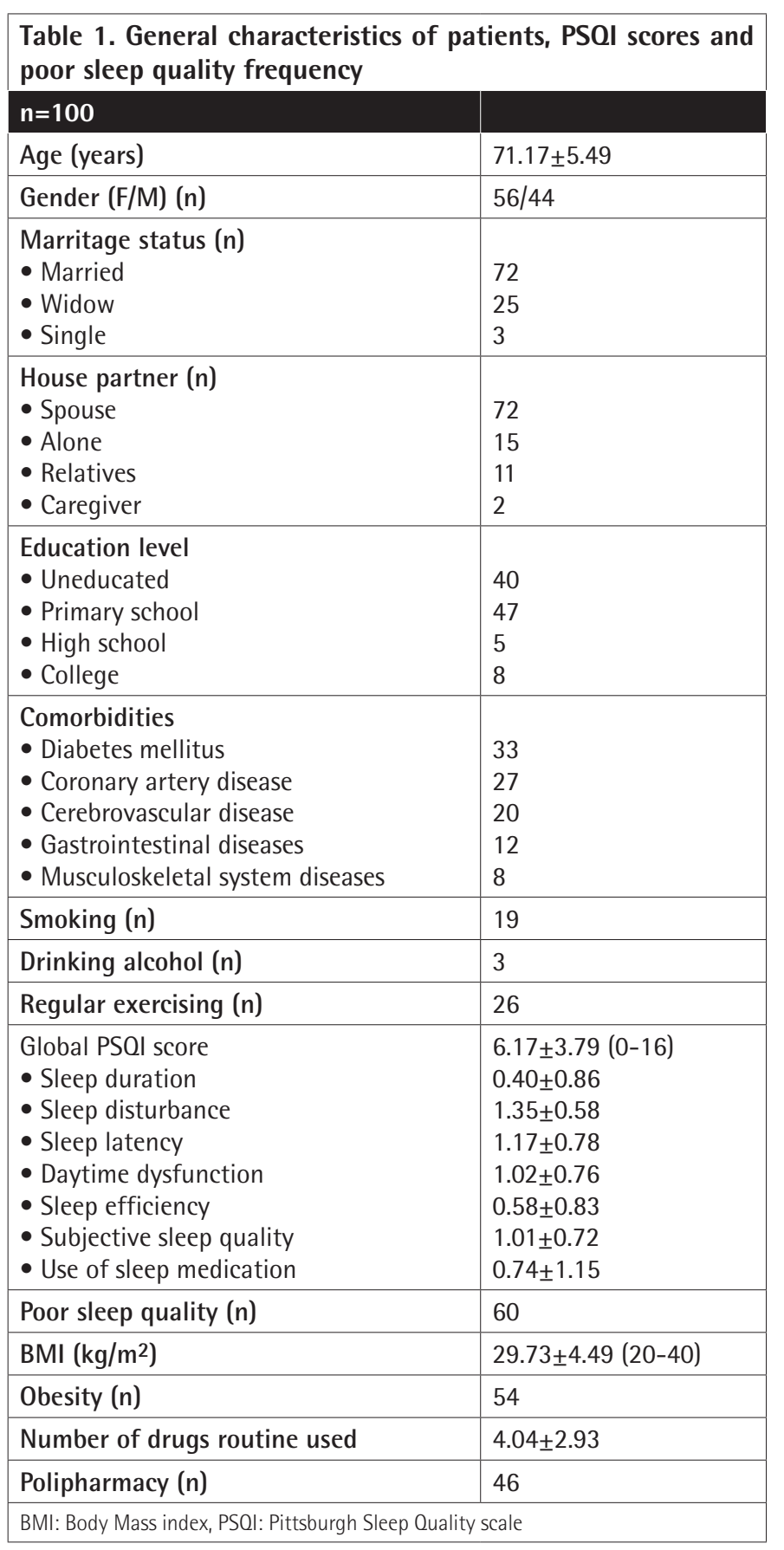

In the literature, obesity is the most important disease seen as a result of sleep disorders (17). The decrease in sleep time causes an increase in the circulating ghrelin level and a decrease of the leptin level. As a result, energy expenditure decreases, appetite, and therefore the risk of obesity increase (16). Studies have shown that there is a relationship between sleep disorder, sleep deprivation, and BMI (18). In the community-based Wisconsin Cohort Sleep study conducted by Taheri and Thomas (19), which included 1.024 people, it was found that the participants slept less than 8 hours and the duration of sleep decreased as the BMI increased. In the Valencia-Spain Health and nutrition survey, a cross-sectional study involving 1.772 people over the age of 15 , less than half of the individuals stated that they slept 9 hours and more, and the rest 6 hours and less. Those who slept less were found to be at risk for obesity (18). The results of our study also support the relationship between obesity and impaired sleep quality in geriatric patients.

In the aging process, organ functions decrease and the number of chronic diseases increases.

In a recent study from our country, the frequency of polypharmacy in patients who applied to the geriatric outpatient clinic was $59.8 \%$ (20). In a recent study in our country, a statistically significant $(p=0.021)$ correlation was shown between sleep disorders and polypharmacy (21). The results of our study also show that there is a high frequency of polypharmacy in geriatric patients and proves that there is a relationship between polypharmacy and impaired sleep quality.

Depression is one of the common mental disorders in the elderly. It is an important factor affecting the quality of life with various diseases or alone. Generally, in addition to slowing down in mental processes, it causes important but reversible impairment in high cognitive functions such as short-term memory, learning, voluntary attention, and purposeful functions. If depression is not treated, it causes consequences such as death at an early age and deterioration in general health status and the quality of life of the elderly increases with appropriate treatment (22). The reason why depressive patients seek support is generally insomnia, and improvement of sleep disturbance is an important determinant of compliance with treatment. Apart from the discomfort they cause, sleep problems can lead to burnout, poor functionality throughout the day, accidents, and are associated with an increased risk of suicide (23). Sleep changes can also affect mood disorders. It was observed that people who reported insomnia both at the initial interview and during the one-year follow-up were more likely to develop a new major depression than those who recovered at the second interview (24). For these reasons, depression and sleep disturbance are conditions that should be evaluated together. The results of our study also support the relationship between the high GDS and impaired sleep quality in geriatric patients. 


\begin{tabular}{|c|c|c|c|}
\hline$n=100$ & Poor sleep quality $(n=60)$ & Normal sleep quality $(n=40)$ & p \\
\hline Age (years) & $70.70 \pm 5.31$ & $71.87 \pm 5.76$ & $>0.05$ \\
\hline Gender (F/M) (\%) & $73.3 / 26.7$ & $35 / 65$ & 0.000 \\
\hline $\begin{array}{l}\text { Marritage status (\%) } \\
\text { - Married } \\
\text { - Widow } \\
\text { - Single }\end{array}$ & \begin{tabular}{|l}
66.7 \\
28.3 \\
5 \\
\end{tabular} & $\begin{array}{l}80 \\
20 \\
- \\
\end{array}$ & $>0.05$ \\
\hline $\begin{array}{l}\text { House partner (\%) } \\
\text { - Spouse } \\
\text { - Alone } \\
\text { - Relatives } \\
\text { - Caregiver }\end{array}$ & \begin{tabular}{|l|}
66.7 \\
15 \\
15 \\
3.4 \\
\end{tabular} & $\begin{array}{l}80 \\
15 \\
5 \\
- \\
\end{array}$ & $>0.05$ \\
\hline $\begin{array}{l}\text { Education level } \\
\text { - Uneducated } \\
\text { - Primary school } \\
\text { - High school } \\
\text { - College }\end{array}$ & \begin{tabular}{|l|}
51.7 \\
35 \\
6.7 \\
6.7 \\
\end{tabular} & \begin{tabular}{|l}
35 \\
52.5 \\
2.5 \\
10 \\
\end{tabular} & $>0.05$ \\
\hline $\begin{array}{l}\text { Comorbidities } \\
\text { - Diabetes mellitus } \\
\text { - Coronary artery disease } \\
\text { - Cerebrovascular disease } \\
\text { - Gastrointestinal diseases } \\
\text { - Musculoskeletal system diseases }\end{array}$ & \begin{tabular}{|l|}
36.7 \\
23.3 \\
21.7 \\
8.3 \\
10 \\
\end{tabular} & $\begin{array}{l}27.5 \\
32.5 \\
17.5 \\
17.5 \\
5 \\
\end{array}$ & $>0.05$ \\
\hline Global PSOI score & $7.83 \pm 3.97$ & $4.76 \pm 3.09$ & 0.000 \\
\hline Smoking (\%) & 20 & 17.5 & $>0.05$ \\
\hline Drinking alcohol (\%) & 1.7 & 5 & $>0.05$ \\
\hline Regular exercising (\%) & 23.3 & 30 & $>0.05$ \\
\hline BMI $\left(\mathrm{kg} / \mathrm{m}^{2}\right)$ & $31.10 \pm 4.50$ & $27.69 \pm 3.66$ & 0.000 \\
\hline Obesity (\%) & 80.4 & 42.6 & 0.000 \\
\hline Number of drugs routine used & $4.84 \pm 3.05$ & $2.88 \pm 2.32$ & 0.002 \\
\hline Polipharmacy (\%) & 58.3 & 27.5 & 0.004 \\
\hline ADL (/100 points) & $61.41 \pm 17.96$ & $78.33 \pm 15.63$ & $>0.05$ \\
\hline IADL (/17 points) & $8.471 \pm 3.52$ & $5.12 \pm 2.42$ & 0.025 \\
\hline MMSE & $25.12 \pm 2.11$ & $25.87 \pm 2.19$ & $>0.05$ \\
\hline GDS & $4.88 \pm 4.11$ & $2.57 \pm 3.14$ & 0.003 \\
\hline Walking speed $(\mathrm{m} / \mathrm{s})$ & $0.66 \pm 0.35$ & $0.88 \pm 0.46$ & 0.011 \\
\hline MNA-SF & $10.80 \pm 2.76$ & $11.67 \pm 2.15$ & $>0.05$ \\
\hline Handgrip strength & $20.24 \pm 8.82$ & $27.98 \pm 11.41$ & 0.000 \\
\hline
\end{tabular}

Sarcopenia is one of the important health problems frequently seen in the elderly. While the prevalence of sarcopenia is $5-25 \%$ in individuals aged $60-70$ years, it is $11-50 \%$ in individuals over 80 years of age (25). This age-specific condition increases the risk for the poor quality of life, risk of falling, and negative outcomes that can result in death. Physical inactivity, prolonged bed rest, sedentary life, limitation of movement, or loss of mobility increase sarcopenia (26). Due to physical inactivity, sarcopenia occurs and creates a vicious circle, causing adverse effects on the body. In order to diagnose sarcopenia, the variables that need to be measured are; muscle mass, muscle strength, and physical performance (27). In our study, when we measured muscle strength and walking speed, two important elements of the diagnosis of sarcopenia, we found that muscle strength and walking speed were significantly lower in elderly patients with poor sleep quality $(p<0.005)$. When we scan the literature as sleep disorders and sarcopenia, we see the recent studies of Ida et al. (28) friends in 318 elderly diabetic patients. As a result of this study, they showed that there was a positive correlation between sarcopenia and sleep 
disorders (28). Furthermore, few studies have examined the relationship between various sleep parameters and muscle power, such as sleep quality, sleep fragmentation, diurnal variation, use of sedative agents, and primary sleep disorders (26-29). The results of our study also support the relationship between decreased muscle strength and walking speed and impaired sleep quality in geriatric patients.

\section{Study Limitations}

There are some important limitations in our study. The most important of these is that the decrease in sleep quality is evaluated only subjectively. The inadequate size of the sample group prevented the generalization of the results. Finally; the existing chronic diseases of individuals participating in the study may have caused a decrease in their sleep quality. However, the proportion of the elderly who do not have a chronic disease is quite low in the population. The quality of sleep is impaired in the majority of geriatric patients. Obesity, depressive mood, polypharmacy, and female gender appear to be the most important factors affecting sleep quality.

\section{Conclusion}

It is thought that the quality of life of the elderly will increase with the evaluation of the sleep quality and intervention planning to increase it by the healthcare professionals taking care of older individuals if necessary.

\section{Ethics}

Ethics Committee Approval: Ethical approval was obtained. The study was carried out in accordance with the Helsinki Declaration (Gaziantep University Faculty of Health Sciences, protocol no: 218).

Informed Consent: Patient consent form was not received as it is a retrospective study.

Peer-review: Externally and internally peer-reviewed.

\section{Authorship Contributions}

Surgical and Medical Practices: I.H.T., Concept: Z.A.Ö., Design: Z.A.Ö., Data Collection or Processing: A.Ç., Analysis or Interpretation: I.H.T., Literature Search: E.M.E., Writing: A.Ç.

Conflict of Interest: The authors have no conflicts of interest to report.

Financial Disclosure: The authors declared that this study received no financial support.

\section{References}

1. Frohnhofen H, Popp R, Stieglitz S, Netzer N, Danker-Hopfe H. Assessment of sleep and sleep disorders in geriatric patients. Z Gerontol Geriatr 2020;53:100-104.
2. Zhou G, Liu S, Yu X, Zhao X, Ma L, Shan P. High prevalence of sleep disorders and behavioral and psychological symptoms of dementia in lateonset Alzheimer disease: A study in Eastern China. Medicine (Baltimore) 2019;98:18405.

3. Liu X, Chen J, Zhou J, Liu J, Lertpitakpong C, Tan A, Wu S, Mao Z. The Relationship between the Number of Daily Health-Related Behavioral Risk Factors and Sleep Health of the Elderly in China. Int J Environ Res Public Health 2019;16:4905.

4. Hayashino $Y$, Fukuhara $S$, Suzukamo $Y$, Okamura $T$, Tanaka $T$, Ueshima $H_{i}$ HIPOP-OHP Research group. Relation between sleep quality and quantity, quality of life, and risk of developing diabetes in healthy workers in Japan: the High-risk and Population Strategy for Occupational Health Promotion (HIPOP-OHP) Study. BMC Public Health 2007;7:129.

5. Buysse DJ, Reynolds CF, Monk TH, Berman SR, Kupfer DJ. The Pittsburgh Sleep Quality Index: a new instrument for psychiatric practice and research. Psychiatry Res 1989;28:193-213.

6. West SD, Nicoll DJ, Stradling JR. Prevalence of obstructive sleep apnoea in men with type 2 diabetes. Thorax 2006;61:945-950.

7. Fiorentini $A$, Valente R, Perciaccante A, Tubani L. Sleep's quality disorders in patients with hypertension and type 2 diabetes mellitus. Int J Cardiol 2007;114:50-52.

8. Yesavage JA, Brink $T L$, Rose $T L$, Lum 0 , Huang $V$, Adey $M$, Leirer VO. Development and validation of a geriatric depression screening scale: a preliminary report. J Psychiatr Res 1982-1983;17:37-49.

9. Folstein MF, Lee R, Helzer JE. Harshaw Chemical Company, Cleve and abnormal populations . ing respiration Washington University ( St Louis ) as. 1983;7:2014.

10. Mahoney Fi, Barthel Dw. Functional Evaluation: The Barthel Index. Md State Med J 1965;14:61-65.

11. Lawton MP, Brody EM. Assessment of older people: self-maintaining and instrumental activities of daily living. Gerontologist 1969;9:179-186.

12. Soysal P, Veronese $N$, Arik F, Kalan U, Smith L, Isik AT. Mini Nutritional Assessment Scale-Short Form can be useful for frailty screening in older adults. Clin Interv Aging 2019;14:693-699.

13. Praharaj SK, Gupta R, Gaur N. Clinical Practice Guideline on Management of Sleep Disorders in the Elderly. Indian J Psychiatry 2018;60:383-396.

14. Rodriguez JC, Dzierzewski JM, Alessi CA. Sleep problems in the elderly. Med Clin North Am 2015;99:431-439.

15. Lo CM, Lee PH. Prevalence and impacts of poor sleep on quality of life and associated factors of good sleepers in a sample of older Chinese adults. Health Qual Life Outcomes 2012;10:72.

16. Taheri S, Lin L, Austin D, Young T, Mignot E. Short sleep duration is associated with reduced leptin, elevated ghrelin, and increased body mass index. PLoS Med 2004;1:62.

17. Cappuccio FP, Taggart FM, Kandala NB, Currie A, Peile E, Stranges S, Miller MA. Meta-analysis of short sleep duration and obesity in children and adults. Sleep 2008;31:619-626.

18. Phillips BA. Inadequate Sleep as a Risk Factor for Obesity: Analyses of the NHANES I. Yearb Pulm Dis 2007;2007:307-309.

19. Taheri $\mathrm{S}$, Thomas GN. Is sleep duration associated with obesity-where do U stand? Sleep Med Rev 2008;12:299-302.

20. Kaya D, Koçyiğit SE, Dokuzlar Ö, Soysal P, Işık AT. Geriatri poliklinik olgularında geriatrik sendromlar: 1048 olgunun analizi. Ege Tıp Derg 2018;57:31-35.

21. Kücükdagli P. Polypharmacy and Related Factors in Geriatric Outpatients. Eur J Geriatr Gerontol 2019;1:56-60.

22. Lee JE, Kim YJ, Park HJ, Park S, Kim H, Kwon O. Association of recommended food score with depression, anxiety, and quality of life in Korean adults: the 2014-2015 National Fitness Award Project. BMC Public Health 2019;19:956. 
23. Ağargün MY, Kara $H$, Solmaz M. Subjective sleep quality and suicidality in patients with major depression. J Psychiatr Res 1997;31:377-381.

24. Ford DE, Kamerow DB. Epidemiologic study of sleep disturbances and psychiatric disorders. An opportunity for prevention? JAMA 1989;262:14791484.

25. Janssen I. Influence of sarcopenia on the development of physical disability: the Cardiovascular Health Study. J Am Geriatr Soc 2006;54:56-62.

26. Alexandre Tda S, Duarte YA, Santos JL, Wong R, Lebrão ML. Prevalence and associated factors of sarcopenia among elderly in Brazil: findings from the SABE study. J Nutr Health Aging 2014;18:284-290.

27. Cruz-Jentoft AJ, Baeyens JP, Bauer JM, Boirie $Y$, Cederholm T, Landi $F$, Martin FC, Michel JP, Rolland Y, Schneider SM, Topinková E, Vandewoude
M, Zamboni M; European Working Group on Sarcopenia in Older People. Sarcopenia: European consensus on definition and diagnosis: Report of the European Working Group on Sarcopenia in Older People. Age Ageing 2010;39:412-423.

28. Ida $S$, Kaneko $R$, Nagata $H$, Noguchi $Y$, Araki $Y$, Nakai $M$, Ito $S$, Ishihara $Y$, Imataka K, Murata K. Association between sarcopenia and sleep disorder in older patients with diabetes. Geriatr Gerontol Int 2019;19:399-403.

29. Buchmann N, Spira D, Norman K, Demuth I, Eckardt R, Steinhagen-Thiessen E. Schlaf, Muskelmasse und Muskelfunktion im Alter. Dtsch Arztebl Int 2016;113:253-260. 